\title{
Is Transfusion an Independent Predictive Risk Factor of Postoperative Outcome in Pediatric Orthopedic Surgical Patients? A Retrospective Study
}

\begin{abstract}
Background: Intraoperative and postoperative morbi-mortality factors are multiple in pediatric patients. Studies in pediatric cardiac surgery and intensive care patients have identified transfusion as one independent factor among others.
\end{abstract}

Objectives: To investigate whether transfusion was an independen risk factor of postoperative outcome in pediatric orthopedic surgical patients. study.

Design: Retrospective observational descriptive pediatric cohor

Setting: Monocentric pediatric tertiary center, Necker University Sick Children's Hospital Paris, from 1 January 2014 to 17 May 2017.

Patients: 195 patients with a median age of 144 months [106.5178.5] were included.

Inclusion criteria was the presence or the absence of transfusion in the intraoperative period in orthopedic surgery.

Exclusion criterion was transfusion in the postoperative period unti discharge from hospital.

Main outcome measures: Primary outcome was morbidity in transfused and nontransfused patients. Morbidity was assessed by deaths, complications and repeat surgery occuring intraoperatively or postoperatively during the entire hospitalization.

Secondary outcome was assessed by length of stay in the intensive care unit, in the hospitalisation ward, total length of stay in hospital and duration of mechanical ventilation.

Statistical analysis: Multiple logistic and log-linear regressions were used to assess for independent predictors of outcome.

Results: ASA score [odds ratio 2.73, p-value $<0.01$ ] and transfusion [odds ratio 1.98, $\mathrm{p}$-value $<0.01$ ] were independent predictive risk factors for complications.

Emergency surgery [odds ratio 7.62, p-value $<0.01$ ] was the independent predictive risk factor for repeat surgery. ASA score transfusion and emergency surgery [p-value $<0.01]$ were independent predictive risk factors for length of stay in the intensive care unit and length of stay in hospital. ASA score, transfusion and age [p-value $<0.01$ ] were independent predictive risk factors for length of mechanical ventilation. There was no mortality in this cohort.

Conclusions: Transfusion was an independent predictive risk factor among others for postoperative outcome. Specific measures aiming to reduce exposure to blood products in potential hemorrhagic surgery like scoliosis can improve outcome.

\section{Introduction}

In pediatric patients admitted for surgery under anesthesia, morbi-mortality is related to mutiple factors. Several morbi-mortality risk factors have been identified of which transfusion is one of the

\section{Journal of}

\section{Emergency Medicine \& Critical Care}

\author{
Kumba $C^{1 *}$, Lenoire $A^{1}$, Cairet $P^{1}$, Dogaru-Dedieu $E^{1}$, \\ Belloni I ${ }^{1}$ and Orliaguet $\mathrm{G}^{2}$
}

${ }^{\prime}$ Department of Pediatric Anesthesia and Critical Care, Necker University Sick Children's Hospital, Paris, Paris Descartes (Paris V) University, France

${ }^{2}$ Department of Anesthesia and Critical Care, Department of Pharmacology and Therapeutic Evaluation in Children and Pregnant Women, Necker University Sick Children's Hospital, Paris Descartes (Paris V) University, France

\section{Address for Correspondence}

Kumba C, Department of Pediatric Anesthesia and Critical Care, Necker University Sick Children's Hospital, Paris, Paris Descartes (Paris V) University, France, E-mail: claudine.kumba@gmail.com

Submission: 20 June, 2018

Accepted: 21 July, 2018

Published: 30 July, 2018

Copyright: $\odot 2018$ Kumba C, et al. This is an open access article distributed under the Creative Commons Attribution License, which permits unrestricted use, distribution, and reproduction in any medium, provided the original work is properly cited.

independent risk factors in studies concerning pediatric cardiac surgery and critical care patients [1-3]. This present study was undertaken to determine whether transfusion was an independent morbidity risk factor in pediatric orthopedic patients. The primary endpoint was to identify factors related to morbidity and the secondary endpoint was to identify factors related to length of stay in the intensive care unit (LOSICU), length of stay in hospital (LOSHOSP), total length of stay in hospital (intensive care and standard hospitalisation ward, TLOSHOSP) and duration of mechanical ventilation (LMV)in this pediatric population.

\section{Methods}

After approval from the Ethics Committee of Necker University Sick Children's Hospital, Paris, France, under the registration number 2017-CK-5-R1 on 21 March 2017and after declaration of this study to the National Commission of Liberties and Computer Science, Paris, France (CNIL, Commission Nationale des Libertéset del'Informatique) under the registration number $2028257 \mathrm{v} 0$ on 21 February 2017, 195 patients with a median age of 144 months [106.5178.5] were included in this study from Necker University Sick Children's hospital.

Inclusion criteria consisted of patients admitted retrospectively for orthopedic surgery and who received blood products [packed red blood cells (PRBC) and/or fresh frozen plasma (FFP) and/ or concentrated platelet units (CPU)] in the intraoperative period (transfusion group) and patients admitted for the same surgical speciality and who did not receive any blood transfusion during surgery orin the postoperative period.

We first included patients who received blood products [packed red blood cells (PRBC) and/or fresh frozen plasma (FFP) and /or concentrated platelet units (CPU)] in the intraoperative period (transfusion group), and then patients who did not receive blood components, in order to include patients with same surgical 
Citation: Kumba C, Lenoire A, Cairet P, Dogaru-Dedieu E, Belloni I, et al. Is Transfusion an Independent Predictive Risk Factor of Postoperative Outcome in Pediatric Orthopedic Surgical Patients? A Retrospective Study. J Emerg Med Critical Care 2018;4(2): 7.
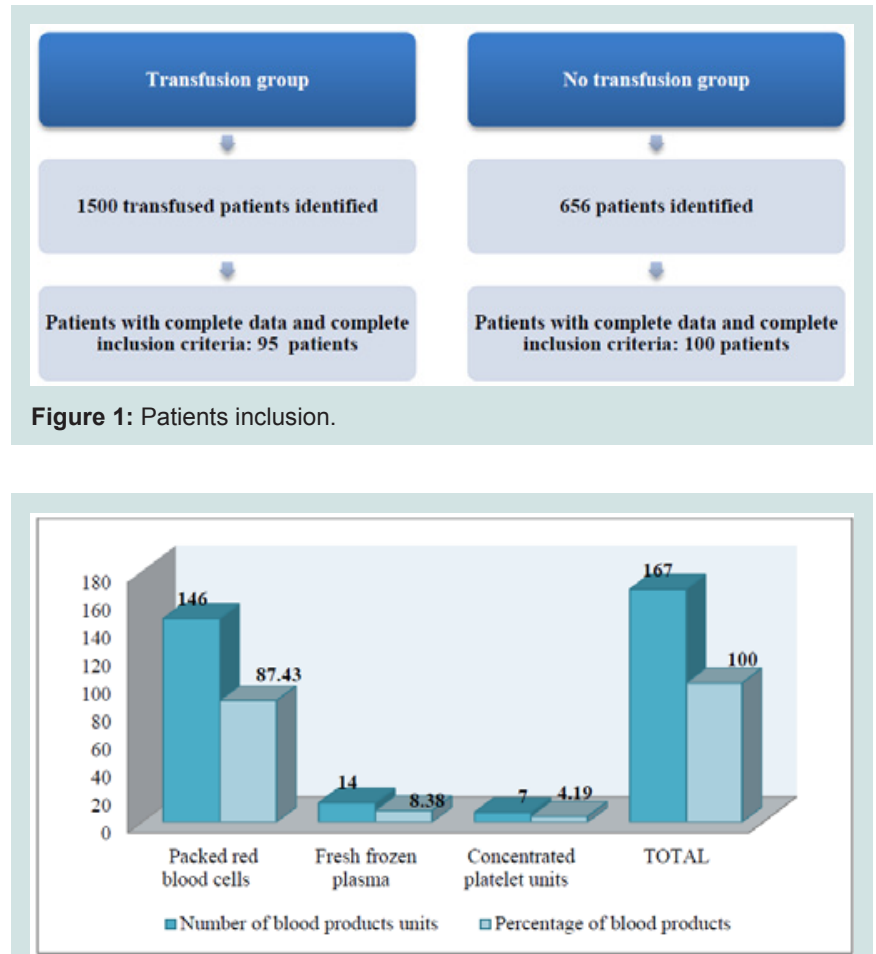

Figure 2: Distribution of blood products administered in orthopedic patients.

operations whenever possible.

The local Transfusion Department provided a list of patients who had been transfused in the operation theatre from 1 January 2014 until 31 December 2016.

There were 1500 transfused patients identified of which only 95 were finally retained for the study because of complete data and complete inclusion criteria (Figure 1).

We used the operation theatre programmation system (IPOP) to identify patients who did not receive blood products intraoperatively and postoperatively. 656 patients were identified from 1 January 2014 until May 2017 and 100 were included in the no transfusion group; these patients had similar characteristics and interventions whenever possible as those in the transfusion group (Figure 1).

Medical records were analyzed using the computer medical report system (Orbis, Mediweb and Cristalnet).

Data collected consisted of intraoperative and postoperative deaths, complications which included organ failure, infections and repeat surgery regardless of TLOSHOSP (to assess primary outcome); number of days spent in the intensive care unit and in the hospitalisation ward, total number of days spent in hospital, number of days spent under mechanical ventilation (to assess secondary outcome).

Factors that could influence primary and secondary outcomes were collected : age, prematurity, type of surgery, comorbidities, ASA score (American Society of Anesthesiologists Score), emergency surgery, number of units of blood products administered [packed red blood cell units (PRBC), fresh frozen plasma units (FFP), concentrated platelet units (CPU], preoperative and postoperative hemoglobin and platelet concentration. The ASA score (I-V) is a scale used in anesthesia to assess patient severity physical status:

\section{ASA I: Normal healthy patient;}

2. ASA II: Patient with mild systemic disease;

3. ASA III: Patient with severe systemic disease

4. ASA IV: Patient with severe systemic disease which is constantly threatening life;

5. ASA V: Moribund patient who is not expected to survive without surgery

Missing data concerning patient weight, intraoperative blood loss and fluid therapy with crystalloids and colloids, coagulation analysis like international normalized ratio, activated partial thromboplastin time, fibrinogen blood levels which could influence blood transfusion were not taken in to account since they were not always available.

XLSTAT 2018.3 software was used for statistics.

Statistical tests included Student's test for parametrical variables, Chi square or Fischer's exact test to compare category variables; propensity score matching analysis to assess for confounding morbidity factors, logistic and log-linear regressions for multivariate analysis. We considered significant a p-value equals to or less than 0.05 .

We firstly identified risk factors with univariate analysis. Secondly we proceeded with multivariate measures: logistic and loglinear regressions to assess for independent predictive risk factors of outcome [4].

Variables were expressed in mean values with standard deviation $( \pm \mathrm{SD})$ or in median values with the interquartile range between the first and the third quartiles [q1-q3].

Category variables are expressed as proportions.

Four risk factors were identified [ASA score, emergency surgery transfusion (units of blood products administered PRBC+FFP+CUP) and age] and correlated to the number of deaths (mortality) during hospitalisation, number of patients with intraoperative and postoperative complications (complications), repeat surgery, number of days spent in the intensive care unit (LOSICU), in the hospitalisation ward(LOSHOSP), total number of days spent in hospital (ICU plus hospitalisation ward, TLOSHOSP), and the number of days spent under mechanical ventilation (LMV).

Hemoglobin and platelet levels were not taken in to account for analysis since some of the data was not available.

\section{Results}

We included 195 patients, 95 transfused and 100 without transfusion. Table 1 illustrates some characteristics in the transfused and nontransfused patients in univariate analysis. There were no deaths and no premature patients in the two groups.

The median age was not different between the two groups. The number of patients with complications, the number of repeat surgery, the median LOSICU, LOSHSOP, TLOSHOSP, LMV, the number 
Citation: Kumba C, Lenoire A, Cairet P, Dogaru-Dedieu E, Belloni I, et al. Is Transfusion an Independent Predictive Risk Factor of Postoperative Outcome in Pediatric Orthopedic Surgical Patients? A Retrospective Study. J Emerg Med Critical Care 2018;4(2): 7.

ISSN: $2469-4045$

Table 1: General characteristics in transfused and non transfused orthopedic patients.

\begin{tabular}{|c|c|c|c|}
\hline & Transfusion group $(\mathrm{T})$ & No Transfusion group (NT) & p-value \\
\hline Number of patients with complications & 33 & 6 & $<0.0001$ \\
\hline Number of repeat surgery & 11 & 3 & 0.02 \\
\hline Number of deaths & 0 & 0 & \\
\hline $\begin{array}{l}\text { Median length of stay in the intensive care unit in days [interquartile } \\
\text { range] }\end{array}$ & $5[3-7]$ & $0[0-4]$ & $<0.0001$ \\
\hline Median total length of stay in hospital in days [interquartile range] & $18[12-23.5$ & $8[4.75-10.25$ & $<0.0001$ \\
\hline Mechanical ventilation median length in days [interquartile range] & $1[0-1]$ & $0[0-0]$ & $<0.0001$ \\
\hline Number of ASA I patients & 2 & 0 & \\
\hline Number of ASA II patients & 14 & 66 & $<0.0001$ \\
\hline Number of ASA III patients & 57 & 33 & $<0.0001$ \\
\hline Number of ASA V patients & 0 & 0 & \\
\hline $\begin{array}{l}\text { Median number of blood component units per patient [interquartile } \\
\text { range] }\end{array}$ & $1[1-2]$ & $0[0-0]$ & $<0.0001$ \\
\hline Median age in months [interquartile range] & $148[109.5-179.5]$ & $144[97-177]$ & 0.1 \\
\hline Number of premature patients & 0 & 0 & \\
\hline Number of emergency operations & 11 & 0 & $<0.001$ \\
\hline Total number of patients & 95 & 100 & 1 \\
\hline
\end{tabular}

Table 2: Type of surgery.

\begin{tabular}{|c|c|c|}
\hline Type of Surgery & Transfusion group & No Transfusion Group \\
\hline Scoliosis & 63 & 61 \\
\hline Limb amputation & 2 & 0 \\
\hline Femoral osteotomy & 5 & 6 \\
\hline Tumor resection & 11 & 22 \\
\hline Knee prothesis & 1 & 1 \\
\hline Polytrauma & 2 & 0 \\
\hline Femoral Prothesis & 2 & 0 \\
\hline Vertebral arthrodesis/ laminectomy & 1 & 0 \\
\hline Interscapular thoracic desarticulation & 3 & 3 \\
\hline Corset & 0 & 4 \\
\hline Total & 95 & 100 \\
\hline$p$-value & & \\
\hline
\end{tabular}

Table 3: Type of surgery and the number of blood units per patient.

\begin{tabular}{|c|c|c|}
\hline Type of surgery & Number of patients & $\begin{array}{c}\text { Mean blood unit component per } \\
\text { patient } \pm \text { SD }\end{array}$ \\
\hline Scoliosis & 63 & $1.6 \pm 1.17$ \\
\hline Limb amputation & 2 & $1.5 \pm 0.71$ \\
\hline Pelvic osteotomy & 5 & $1.6 \pm 0.55$ \\
\hline Femoral osteotomy & 5 & $1.6 \pm 0.55$ \\
\hline Knee prothesis & 1 & $1 \pm 0$ \\
\hline Polytrauma & 2 & $3 \pm 0$ \\
\hline Femoral prothesis & 2 & $1.5 \pm 0.71$ \\
\hline Vertebral arthrodesis/laminectomy & 1 & $1 \pm 0$ \\
\hline Interscapular thoracic desarticulation & 3 & $2 \pm 1$ \\
\hline
\end{tabular}


Citation: Kumba C, Lenoire A, Cairet P, Dogaru-Dedieu E, Belloni I, et al. Is Transfusion an Independent Predictive Risk Factor of Postoperative Outcome in Pediatric Orthopedic Surgical Patients? A Retrospective Study. J Emerg Med Critical Care 2018;4(2): 7.

ISSN: $2469-4045$

Table 4: Comorbidities.

\begin{tabular}{|c|c|c|}
\hline Comorbidities & Transfusion Group & No Transfusion Group \\
\hline None & 18 & 56 \\
\hline Cerebral palsy & 19 & 11 \\
\hline Osteogenesis Imperfecta & 3 & 2 \\
\hline Psychomotor Deficiency & 7 & 1 \\
\hline Ewing Sarcoma & 14 & 4 \\
\hline Congenital Heart Disease & 1 & 2 \\
\hline Myelomeningocele & 4 & 0 \\
\hline Neurofibromatosis & 5 & 2 \\
\hline Hurler Syndrome & 2 & 0 \\
\hline Epileptic Encephalopathy & 3 & 0 \\
\hline Arcadi Syndrome & 1 & 0 \\
\hline Severe Sepsis & 1 & 0 \\
\hline Lowe Syndrome & 1 & 0 \\
\hline Spinal Muscular Amyotrophy & 2 & 0 \\
\hline Spina Bifida & 1 & 1 \\
\hline Di George Syndrome & 2 & 0 \\
\hline Central Core Myopathy & 1 & 0 \\
\hline Goldenhar Syndrome & 1 & 0 \\
\hline Williams Syndrome & 1 & 0 \\
\hline Pierre-Robin Syndrome & 1 & 1 \\
\hline Muscular Dystrophy & 0 & 2 \\
\hline Polytrauma & 1 & 1 \\
\hline Polymalformative Syndrome & 0 & 4 \\
\hline Prader Willi Syndrome & 0 & 2 \\
\hline Arnold-Chiari Syndrome & 0 & 0 \\
\hline Sarcoïdosis & 0 & 1 \\
\hline Scoliosis & 1 & 0 \\
\hline Pigamentosum Xerodermia & 0 & 1 \\
\hline Gorlin Syndrome & 4 & 0 \\
\hline Total & 95 & 100 \\
\hline p-value & & $<0.0001$ \\
\hline
\end{tabular}

of ASA score status III or more patients, the number of emergency interventions were significantly higher in the transfusion group.

Table 2 illustrates the type of surgery. Scoliosis was the most common intervention, 63 and 61 patients followed by tumor resection with 11 and 23 patients respectively in the transfused and no transfusion group.

Figure 2 illustrates the blood products administered in the transfusion group: PRBC were the most administered (more than $80 \%$ ), followed by FFP (more than $8 \%$ ) and followed by CPU (more than $4 \%)$.

Table 3 shows the mean blood units per patient according to surgery: trauma patients received $3 \pm 0$ units, tumor resection patients received $2.9 \pm 2.5$ units and scoliosis patients received $1.6 \pm 1.17$ units per patient, keeping in mind that scoliosis surgery was the most common intervention with 63 patients and tumor resection the second common with 11 patients of 95 transfused patients.

The most common comorbidity (Table 4) was cerebral palsy in the two groups. Ewing sarcoma was the second common comorbidity in the transfusion group.

Table 5 illustrates the intraoperative and postoperative complications. The most common intraoperative complication was hemorrhagic shock, the most common postoperative organ failure was neurologic followed by respiratory; the most common postoperative infectious complication was urinary sepsis in the 
Citation: Kumba C, Lenoire A, Cairet P, Dogaru-Dedieu E, Belloni I, et al. Is Transfusion an Independent Predictive Risk Factor of Postoperative Outcome in Pediatric Orthopedic Surgical Patients? A Retrospective Study. J Emerg Med Critical Care 2018;4(2): 7.

ISSN: $2469-4045$

Table 5: Complications.

\begin{tabular}{|c|c|c|}
\hline Complications & Transfusion group & No transfusion group \\
\hline Intraoperative hemorrhagic shock & 8 & 0 \\
\hline Intraoperative anaphylaxis & 1 & 0 \\
\hline Intraoperative cardiac arrest & 0 & 0 \\
\hline Intraoperative broncho-laryngospasm & 0 & 0 \\
\hline Intraoperative difficult intubation & 0 & 0 \\
\hline Intraoperative respiratory distress & 1 & 0 \\
\hline \multicolumn{3}{|c|}{ Postoperative organ failure } \\
\hline Neurologic & 8 & 2 \\
\hline Cardiocirculatory & 2 & 1 \\
\hline Respiratory & 4 & 0 \\
\hline Renal & 1 & 0 \\
\hline Endocrinologic & 0 & 0 \\
\hline Multisystemic & 0 & 0 \\
\hline Postoperative hemorrhagic shock & 0 & 0 \\
\hline Deaths & 0 & 0 \\
\hline Repeat surgery & 11 & 3 \\
\hline \multicolumn{3}{|c|}{ Postoperative infectious complications } \\
\hline Pulmonary sepsis & 0 & 1 \\
\hline Abdominal sepsis & 1 & 0 \\
\hline Urinary sepsis & 4 & 0 \\
\hline Mediastinal sepsis & 0 & 0 \\
\hline Neuromeningeal sepsis & 0 & 0 \\
\hline Local wound sepsis & 8 & 2 \\
\hline Septicemia & 3 & 1 \\
\hline Total & 52 & 10 \\
\hline p-value & \multicolumn{2}{|c|}{0.54} \\
\hline
\end{tabular}

Table 6: Propensity score matching for transfusion and emergency surgery.

\begin{tabular}{|l|c|c|c|c|}
\hline Variable & $\begin{array}{c}\text { Number of matched } \\
\text { patients }\end{array}$ & $\begin{array}{c}\text { Percentage of matched } \\
\text { patients }\end{array}$ & $\begin{array}{c}\text { Number of unmatched } \\
\text { patients }\end{array}$ & $\begin{array}{c}\text { Percentage of unmatched } \\
\text { patients }\end{array}$ \\
\hline Transfusion & 95 & $100 \%$ & 0 & $0 \%$ \\
\hline Emergency surgery & 11 & $100 \%$ & 0 & $0 \%$ \\
\hline
\end{tabular}

transfusion group. When comparing the rate of each complication between the two groups, the difference was not significant. However the proportion of patients with complications was significantly higher in the transfusion group $(\mathrm{p}<0.0001$, Table 1$)$.

After propensity score matching analysis, $100 \%$ of the transfused patients and $100 \%$ of patients with emergency surgery were matched (Table 6).

After logistic regression (Table 7), ASA score [odds ratio 2.73, p-value $<0.01$ ] and transfusion [odds ratio 1.98 , p-value $<0.01$ ] were independent predictive risk factors for complications. Emergency surgery [odds ratio 7.62 , p-value $<0.01$ ] was the independent predictive risk factor for repeat surgery.
After log-linear regression (Table 8), ASA score, emergency surgery and transfusion ( $\mathrm{p}$-value $<0.01$ ) were independent predictive risk factors for LOSICU, LOSHOSP and TLOSHOSP. ASA score, transfusion and age ( $\mathrm{p}$-value $<0.01)$ were independent predictive risk factors for LMV.

\section{Discussion}

Our study has shown that in this pediatric orthopedic surgical cohort, perioperative and postoperative morbidity was determined by multiple factors.

We focused on some of these factors: transfusion, ASA score, emergency surgery and age. 
Citation: Kumba C, Lenoire A, Cairet P, Dogaru-Dedieu E, Belloni I, et al. Is Transfusion an Independent Predictive Risk Factor of Postoperative Outcome in Pediatric Orthopedic Surgical Patients? A Retrospective Study. J Emerg Med Critical Care 2018;4(2): 7.

ISSN: $2469-4045$

Table 7: Logistic regression for complications and repeat surgery.

\begin{tabular}{|c|c|c|c|c|}
\hline Independent variable & Dependent variable & Wald value $[95 \%$ confidence interval] & Odds ratio $[95 \%$ confidence interval] & p-value \\
\hline & Complications & & & \\
\hline ASA score & & $1.01[0.39-1.63]$ & $2.73[1.47-5.08]$ & $<0.01$ \\
\hline Emergency & & $0.91[-0.56-2.38]$ & $2.48[0.57-10.75]$ & 0.23 \\
\hline Transfusion & & $0.68[0.29-1.07]$ & $1.98[1.34-2.93]$ & $<0.01$ \\
\hline \multirow[t]{2}{*}{ Age } & & $-0.003[-0.011-0.005]$ & $0.99[0.989-1.005]$ & 0.46 \\
\hline & Repeat surgery & & & \\
\hline ASA score & & $0.65[-0.19-1.49]$ & $1.92[0.83-4.45]$ & 0.13 \\
\hline Emergency & & $2.03[0.50-1.14]$ & $7.62[1.65-35.14]$ & $<0.01$ \\
\hline Transfusion & & $0.13[-0.26-0.52]$ & $1.14[0.77-1.68]$ & 0.51 \\
\hline Age & & $0.001[-0.010-0.012]$ & $1.001[0.99-1.012]$ & 0.87 \\
\hline
\end{tabular}

Table 8: Log linear regression for LOSICU, LOSHOSP, TLOSHOSP and LMV.

\begin{tabular}{|c|c|c|c|}
\hline Independent Variable & Dependent Variable & Wald value $[95 \%$ confidence interval] & p-value \\
\hline & LOSICU & & \\
\hline ASA score & & $0.36[0.25-0.46]$ & $<0.0001$ \\
\hline Emergency & & $0.39[0.15-0.63]$ & $<0.01$ \\
\hline Transfusion & & $0.15[0.11-0.19]$ & $<0.0001$ \\
\hline \multirow[t]{2}{*}{ Age } & & $0.00[-0.001-0.002]$ & 0.64 \\
\hline & LOSHOSP & & \\
\hline ASA score & & $0.20[0.14-0.27]$ & $<0.0001$ \\
\hline Emergency & & $0.22[0.06-0.38]$ & $<0.01$ \\
\hline Transfusion & & $0.15[0.13-0.18]$ & $<0.0001$ \\
\hline \multirow[t]{2}{*}{ Age } & & $0.00[-0.001-0.001]$ & 0.56 \\
\hline & TLOSHOSP & & \\
\hline ASA score & & $0.24[0.18-0.29]$ & $<0.0001$ \\
\hline Emergency & & $0.28[0.15-0.42]$ & $<0.0001$ \\
\hline Transfusion & & $0.16[0.14-0.18]$ & $<0.0001$ \\
\hline \multirow[t]{2}{*}{ Age } & & $0.00[0.00-0.001]$ & 0.40 \\
\hline & LMV & & \\
\hline ASA score & & 0.69 [0.48-0.91] & $<0.0001$ \\
\hline Emergency & & $0.42[-0.011-0.86]$ & 0.06 \\
\hline Transfusion & & $0.37[0.29-0.44]$ & $<0.0001$ \\
\hline Age & & $-0.005[-0.008-0.002]$ & $<0.01$ \\
\hline
\end{tabular}

Complications were mostly predicted by transfusion and ASA score. Optimizing transfusion strategies could improve patient outcome. The physiopathology underlying some transfusion related complications have been already described $[5,6]$.

Exposure to blood products can be reduced by applying restrictive transfusion strategies, using transfusion protocols based on bedside viscoelastic methods to guide blood components administration during hemorrhagic surgery like scoliosis and trauma [7-10]. A study in trauma combat patients showed that ROTEM guided blood product administration significantly improves transfusion practices in damage control resuscitation [11].

Randomized controlled studies are lacking inscoliosis surgery.
One observational prospective study in 210 scoliosis adolescent patients demonstrated that implementation of a perioperative patient blood management program including a goal directed transfusion therapy using thromboelastography reduced red blood cell transfusion [12].

Other measures like intraoperative administration of tranexamic acid, cell salvage, preoperative iron and erythropoietin supplementation can decrease intraoperative blood transfusion in scoliosis surgery [13-15]. Randomized controlled trials concerning reduction in blood transfusion with preoperative iron and erythropoietin supplementation in scoliosis pediatric surgery are lacking. 
Citation: Kumba C, Lenoire A, Cairet P, Dogaru-Dedieu E, Belloni I, et al. Is Transfusion an Independent Predictive Risk Factor of Postoperative Outcome in Pediatric Orthopedic Surgical Patients? A Retrospective Study. J Emerg Med Critical Care 2018;4(2): 7.

ISSN: $2469-4045$

ASA score was an independent predictive factor for complications like LOSHOSP and LMV.

This arise the question if the preoperative ASA score could be improved. Studies in adult surgery have demonstrated patient outcome improvement in surgical patients when a goal directed therapy protocol was used intraoperatively $[16,17]$.

Studies concerning this subject are rare in pediatric surgery and anesthesia and focus should be directed in developing prospective goal directed protocol studies in children to demonstrate whether outcome is improved.

Enhanced pathway recovery protocols reduce postoperative complications and LOSHOSP. These protocols are well developed in adults and are beginning to develop in children [18]. Enhanced pathway recovery protocols in scoliosis pediatric surgery have been studied and have shown to reduce LOSHOSP [19].

Emergency surgery was the independent predictive risk factor for repeat surgery : this is consistent with current literature which showed that complications are more common during emergency surgery than elective surgery [20]. Non urgent interventions should be postponed and performed in office hours.

Our survey showed that transfusion is an independent predictive risk factor of postoperative outcome in this cohort. This finding confirms what has been demonstrated in cardiac and critical care pediatric patients. Transfusion protocols guided by point of care methods in potential hemorrhagic surgery can improve transfusion strategies and thus reduce blood product requirements. Developing intraoperative goal directed fluid therapy protocols and enhanced recovery pathway protocols in children can contribute to reduce postoperative complications and reduce length of hospital stay. Randomized controlled trials are necessary to concretize these practices in children. Our study had limits: firstly it was retrospective with missing data and secondly not all data that could have influenced outcome was analyzed.

\section{References}

1. Willems A, Van Lerberghe C, Gonsette K, De Villé A, Melot C, et al. (2014) The indication for perioperative red blood cell transfusion is a predictive risk factor for severe postoperative morbidity in children undergoing cardiac surgery. Eur J Cardiothorac Surg 45: 1050-1057.

2. Kneyber MC, Hersi MI, Twisk JW, Markhorst DG, Plötz FB (2007) Red blood cell transfusion in critically ill children is independently associated with increased mortlity. Intensive Care Med 33: 1414-1422.

3. Rajasekaran S, Kort E, Hackbarth R, Davis AT, Sanfilippo D, et al. (2016) Red cell transfusions as an independent risk for mortality in crtically ill children. $J$ Intensive Care 4: 2 .

4. Mélot C (2005) Multivariable analyzes: biostatistical note. Respir Dis J 22: 687-690.

5. El Kenz H, Van der Linden P (2014) Transfusion-related acute lung injury. Eur
J Anaesthesiol 31:345-350

6. Mulder HD, Augustijn QJ, van Woensel JB, Bos AP, Juffermans NP, et al (2015) Incidence, risk factors, and outcome of transfusion-related acute lung injury in critically ill children: a retrospective study. J Crit Care 30: 55-59.

7. Lacroix J, Hébert PC, Hutchison JS, Hume HA, Tucci M, et al. (2007) Transfusion strategies for patients in pediatric intensive care units. $N$ Engl $J$ Med 356: 1609-1619.

8. Kozek-Langenecker SA, Afshari A, Albaladejo P, Santullano CA, De Robertis E, et al. (2013) Management of severe perioperative bleeding: guidelines from the European Society of Anaesthesiology. Eur J Anaesthesiol 30: 270382.

9. Nystrup KB, Stensballe J, Bøttger M, Johansson PI, Ostrowski SR (2015) Transfusion therapy in paediatric trauma patients: a review of the literature. Scand J Trauma Resusc Emerg Med 23: 21.

10. Wikkelsø A, Wetterslev J, Møller AM, Afshari A (2016) Thromboelastography (TEG) or thromboelastometry (ROTEM) to monitor haemostatic treatment versus usual care in adults or children with bleeding. Cochrane Database Syst Rev : CD007871.

11. Prat NJ, Meyer AD, Ingalls NK, Trichereau J, DuBose JJ, et al. (2017) Rotational thromboelastometry significantly optimizes transfusion practices for damage control resuscitation in combat casualties. J Trauma Acute Care Surg 83: 373-380.

12. Ohrt-Nissen S, Bukhari N, Dragsted C, Gehrchen M, Johansson PI, et al. (2017) Blood transfusion in the surgical treatment of adolescent idiopathic scoliosis-a single-center experience of patient blood management in 210 cases. Transfusion 57: 1808-1817.

13. Hassan N, Halanski M, Wincek J, Reischman D, Sanfilippo D, et al. (2011) Blood management in pediatric spinal deformity surgery: review of a 2-year experience. Transfusion 51: 2133-2141.

14. Loughenbury PR, Berry L, Brooke BT, Rao AS, Dunsmuir RA, et al. (2016) Benefits of the use of blood conservation in scoliosis surgery. World J Orthop 7: 808-813.

15. Sui W, Ye F, Yang J (2016) Efficacy of tranexamic acid in reducing allogeneic blood products in adolescent idiopathic scoliosis surgery. BMC Musculoskelet Disord 17: 187.

16. Calvo-Vecino JM, Ripollés-Melchor J, Mythen MG, Casans-Francés R, Balik A, et al. (2018) Effect of goal-directed haemodynamic therapy on postoperative complications in low-moderate risk surgical patients: a multicentre randomised controlled trial (FEDORA trial). Br J Anaesth 120: 734-744

17. Ripollés-Melchor J, Varela MLF, Camargo SC, Fernández PJ, Barrio ÁC et al. (2018) Enhanced recovery after surgey protocol versus conventional perioperative care in colorectal surgey. A single center cohort study. Rev Bras Anestesiol S0034-7094: 30389-30396.

18. Rove KO, Edney JC, Brockel MA (2018) Enhanced Recovery after surgery in children : promising evidence-based multidisciplinary care. Pediatr Anaesth $2: 482-492$.

19. Muhly WT, Sankar WN, Ryan K, Norton A, Maxwell LG, et al. (2016) Rapid recovery pathway after spinal fusion for idiopathic scoliosis. Pediatrics 137 : e20151568.

20. de Graaff JC, Sarfo MC, van Wolfswinkel L, van der Werff DB, Schouten AN (2015) Anesthesia-related critical incidents in the perioperative period 